الدلالات الثقافية للمو سيقى الفلكلورية : فرقة العرفة بمنطقة مسيردة أنموذجا

\title{
LAS CONNOTACIONES CULTURALES DE LA MÚSICA FOLKLÓRICA EN ARGELIA: EL GRUPO \\ MUSICAL $A L-A R F A$ COMO MODELO EN LA REGIÓN DE AL-MSIRDA (TREMECÉN)
}

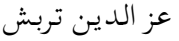

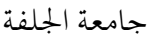 \\ AZEDDINE TERBECH \\ Universidad Zian Achour de Djelfa
}

\begin{abstract}
Resumen
El presente artículo pretende aclarar los conceptos culturales relacionados con la música folklórica argelina. Investiga las raíces del folklore argelino en general y la zona de Tremecén en particular. Estudia las connotaciones culturales del grupo musical al-Arfa y la armonía y el ritmo de los bailes tradicionales en la zona, reflejando y reflexionando sobre la identidad histórica de este arte.
\end{abstract}

Palabras clave: Música folklórica, Argelia, Grupo al-'Arfa, connotaciones culturales, escuela andalusí. 


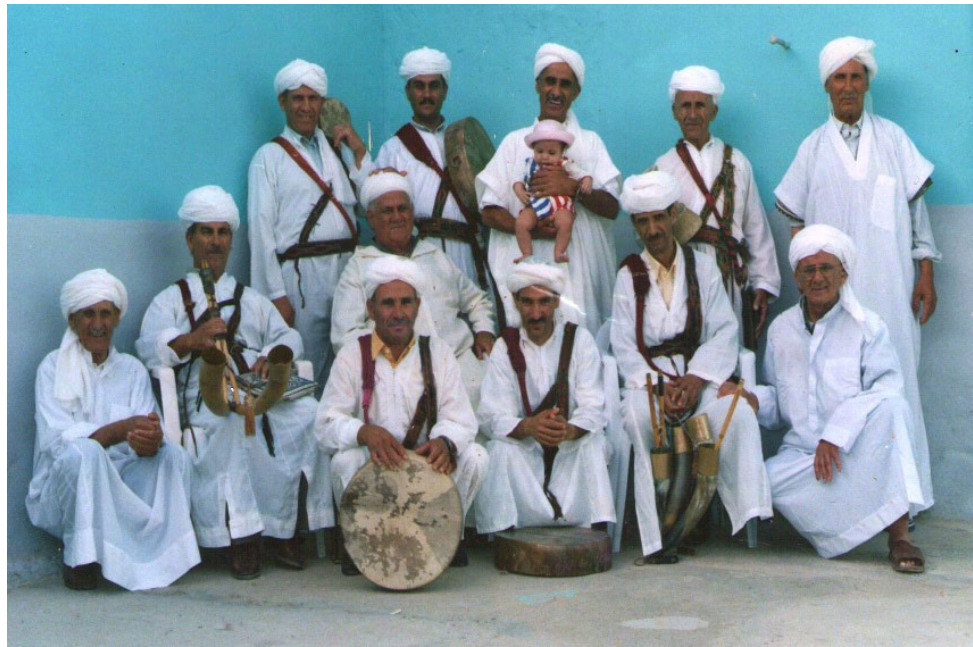

\section{الفرقة الموسيقية " العرفة "}

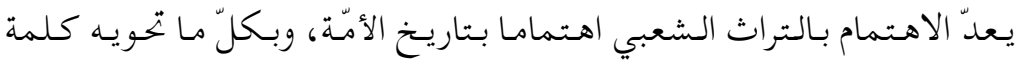
تاريخ من معان، منها : التقاليد والأعراف والعادات والمعاملات الفردية والجماعية،

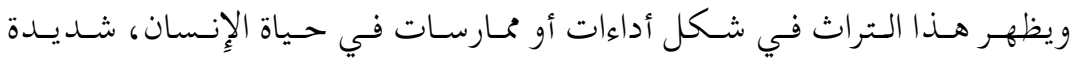
الالتصاق بـه عبر الزّمان و المـكان، وهي بـذلك تمثّل المقوّمات اليومية للثقافة التي

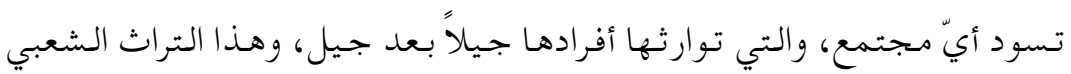

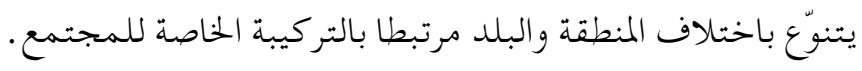

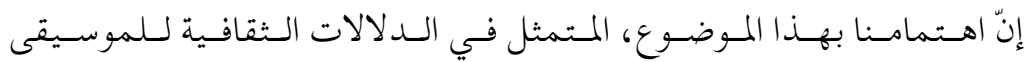
الفلكلورية،التي تهدف إلى تسليط ضَوٍَِ ولو خافتًا على جانب من حضارتنا ذات البعد الشعبي الّذي يبرز لنا حقيقة التعامل والتفكير والتخاطب بين أناس يقيمون في منطقة من مناطق المعمورة، ويقف بنا على عمق النّفس الإِنسانية وخفاياها في تصورّها للحياة و كشف ماضيها. 
وعليه، تظهر أهمية هذه المقالة في الكشف عن المعنى الّذي يكمن وراء تلك الممارسات التي يمارسها أعضاء المجتمع، وتجلية دورها داخل المحتوى الثقافي كافّة

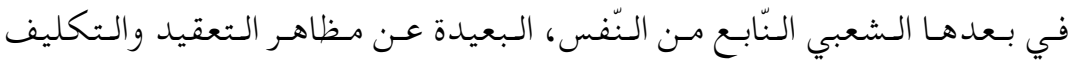

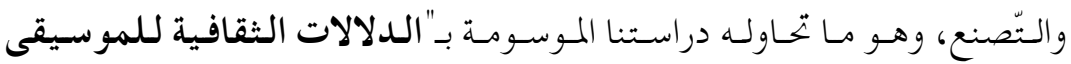
الفلكلورية : فرقة العرفة بمنطقة مسيردة أنموذجا. " إنّ مـا أردنا الوصول إليه بـدراسة هذا الموضوع الّذي امتاز بعراقته و انتقاله عن

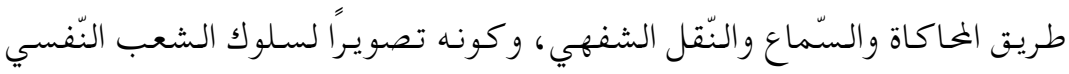
والاجتماعي، ونزوعه إلى التعبير عن روحهه وتقاليده ومعتقده اته دعانا إلى طرح التساؤلات التالية : ماهو موقع الموسيقى في الطّابع الفولكلوري عند فرقة العرفة

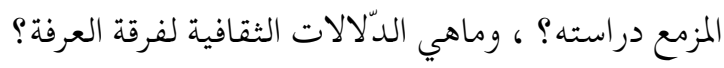

\section{1 تحديد منطقة مسيردة}

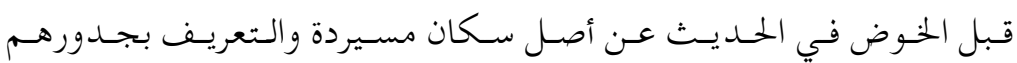
التاريـية والعرقية، ودورهم في رسم المنطقة اقتصاديا واجتماعيا وثقافيا، يـجب أن نحدد موقعهم الجغرافي في الخريطة الجزائرية. إن منطقة مسيردة المعترف بها من السلطات الفرنسية منذ عام1905 إلى غاية

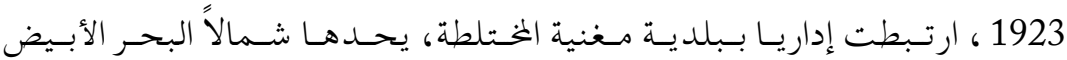
المتوسط، ومـن الشـرق دواويـر السواحسلية، وزاويـة الميرا وتـرنـانـة التابعتين لبلديـة ندرومة الخختلطة، أما جنوبا فتحدها قبائل العشاش والحلدود الجزائرية المغربية، وفق اتفاقية لالة مغنية المؤرخة في 18 مارس 1845 (من المادة الثالثة وتعليلاتها المضافة ببروتو كول أول فبراير1913)، وأمـا غربـا فيحـدهـا كل من دوّار عطية ببو كانون، وواد كـيس، ودوار بــني مـنقوش مـرسى بـن مهـيدي، ومسساحستها تـقدر بـحوالي 
إن مسيردة بمجـموع قراهـا ودواويرهـا تققدم الطابع الجـغرافي الوعر لـشمال

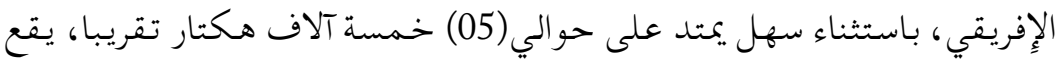

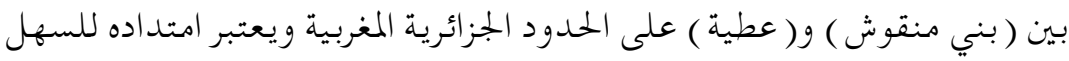
المغربي (تريفة ) وهو على ارتفاع بسيط.

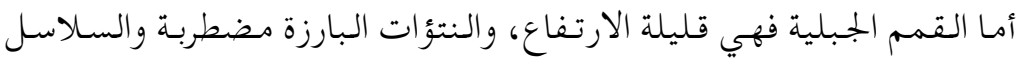
مفرقة بعدد قليل من الأودية الضيقة ذات مداخل صعبة جدلّا، وأهم هذه الأودية، واد الكواردة، ويمكن إحصاء نحو أربعين واديا، وكذا الشعاب التي تجعل الحياة ممرّا

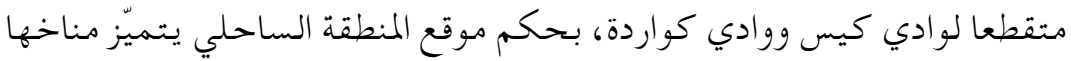
بشتاء بارد وصيف حار وجاف.

\section{2 الجذور التاريخية لسكان منطقة مسيردة}

كما لاشـكّ فيه أن هـذه المنطقة قـد احتفظت بـأثر الأحسداث التي جـرت فيها والخخلفات التي تركتها على تضاريسها، وفي هذا الشأن يقول المستشرق قابريال

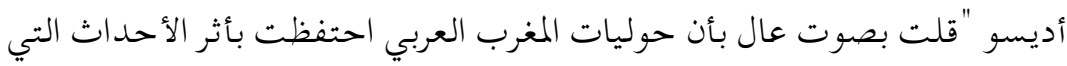

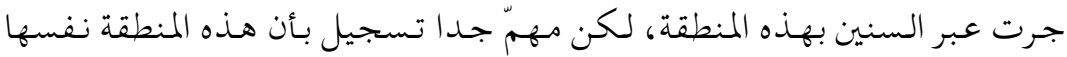
أحدثت أو حملت ذكريات لمراحل قديمة من العصور الوسطى أو ذات أثر قديم" 2.

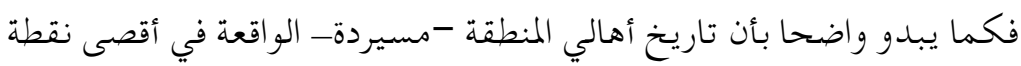

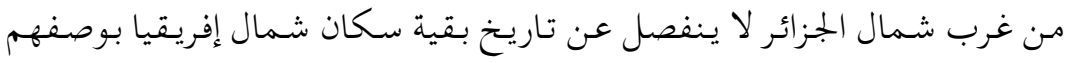

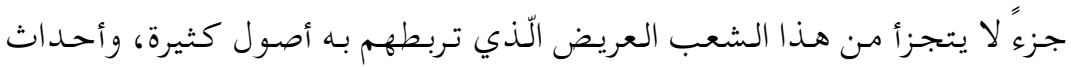

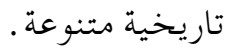

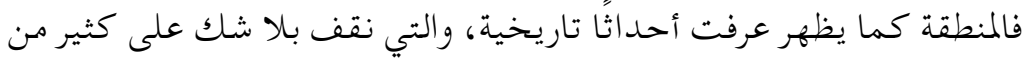

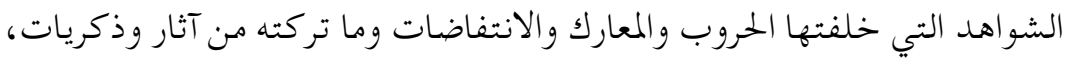

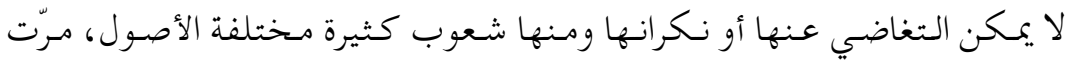


بهذه المنطقة -شمال إفريقيا- نذكر على سبيل المثال الرومان، الوندال الفينيقيين

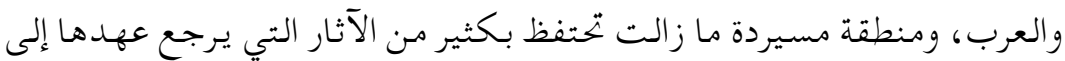
العصور القديمة والمتوسطة، فأما ما يتعلق بـالتسمية -مسيردة- فيروي قابريسيل

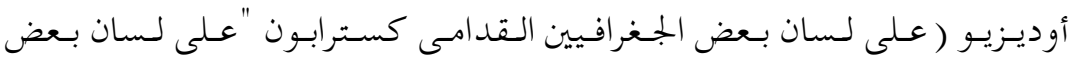
الجغرافيين القدامى كسـترابون "Strabon" ، أن السـكان الّـذيسن يسـتقرون شـرق

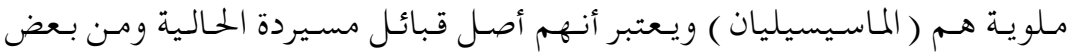
القبائل المجاورة، ويستنتنج الباحـث بـأن المنطقة تعود إلى القرن الثالث مـن عصر موريتانيا القيصرية الرومانية السيزارية 3. ومىن تلك الآثار الرومانية التي لا تزال موجودة في أماكن مختلفة مـن مناطق مسيردة، مثل: باب اللّوح، باب اليهودي، القلعة، وبوزواغي وغير بعيد عن رأس القلعة، في مصب واد الكواردة، في نقطة تسمى ( بلاد تبحريتي )، إنها تعرف كثير من الآثار الرومانية، حيث يظهر بقايا الحي المغربي التبحريتي، والّذي يعنيه البكري في القرن التاسع في بحوثه الجـغرافية، وليون الإِفريقي في وصف إفريقيا و كدا مارمول في كتاباته عن إفريقيا ${ }^{4}$.

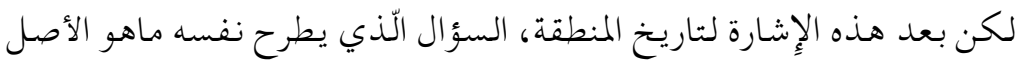
الحقيقي لسكان مسيردة ومن هم؟ في حقيقة الأمر يصعب علينا أن نحدد أصلهم الحقيقي أو إعطاء فكرة مدققة عن هؤلاء السكان من أصليين ولاجئين أو نازحين، فكل ما يلاحظ أنهم يحملون

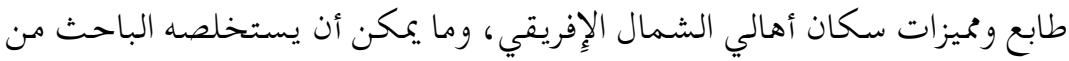
أحاديث المؤرخين ووصف الجغرافيين:" أن هؤلاء السكان برابرة أصلا، وأن القبائل

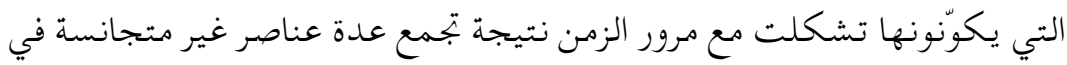

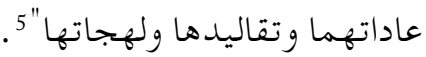


وما يمـكننا أن نميزه اليوم هو عنصريسن مـن سلالتين مختلفتين الأول أصسيل، ويتكون مـن السكان الأصليين لمسيردة والعنابرة والثاني عربي ويتكون مـن أولاد

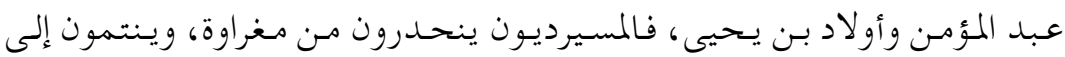
الزيانيين وإلى زيرى بن عطية ومن استقر معه في ضواحي وجدة بالحلدود الجزائرية

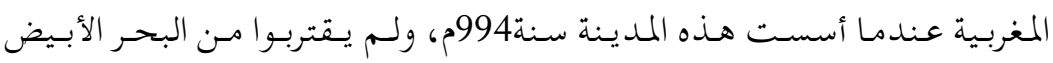
المتوسط إلى في القرن12م، أما العنابرة فينحدرون من يغمراسن مؤسس دولة بني عبد الواد مـن تلمسان، ولم يـضضموا إلى مسـيردة إلاً للتخلص مـن ضغط الأتراك العثمانيين 6

أما في ما يتعلق بالعنصرين العربيين ( أولاد عبد المؤمن،وأولاد بن يحيى ) فِإن ما يربط بينهم هو النسبب الشـيـف أي أحفاد الرسول ( ص ) كما يقال، وأولاد عبد المؤمسن ينسبون إلى إدريس بـينما أولاد بـن يـحيى فينسبون إلى مـولاي عبد القادر الجيلالي.

ومن خلال ما سبق يمكن معرفة الجد الشريف لأحفاد عبد المؤمن الّذي قدم من قرطبة في الـقرن الثالث عشر مارّا بمـدينة سـلا، ومـنطقة ( سوس ) ثم مـنطقة بـن زناسن، حيث خـلف أولادا واستقر كذلك بمـنطقة بـني مـنقوش قرب عجرود ثم نزل بقرية بيدر احدى قرى مسيردة 7. وبالرغم مـن هذه الاحتمالات والاعتقادات فالدارس الباحثث أوديسيو يقول : "قد ثبتت لدى المعرّب الفرنسي والمؤرخ الذي كتب عن تراره ( روني باري ) أن

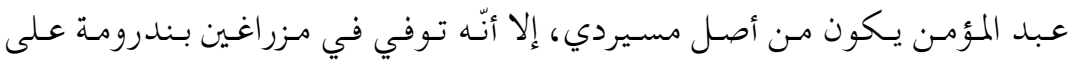
خلاف الاعتقاد الأول ( بـني زنـاسـن ويشـير المؤرخ أن المسجـد الواقع في "بيدر"

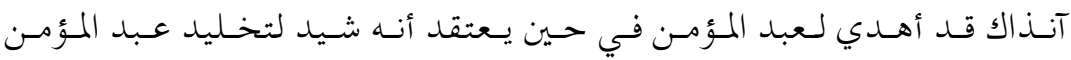

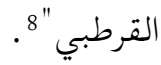




\section{3 مسيردة والاحتلال الفرنسي}

لقد مرت المنطقة بعدة توترات كسائر مناطق أرض الوطن الجزائري، وزاد في

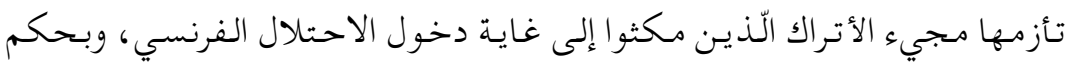

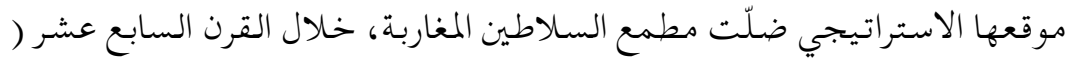

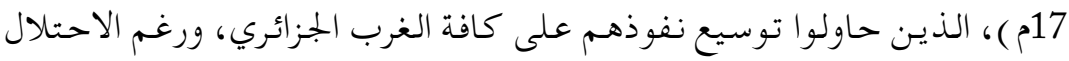

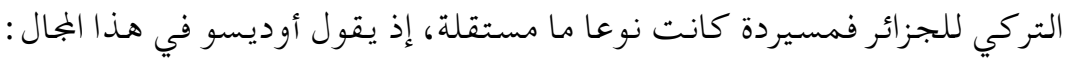

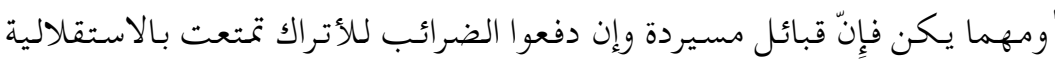

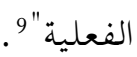

أما الاحتلال الفرنسي لمسيردة، وكما يردد على لسان أهل المنطقة، فلم يكن هينا خصوصا أن هذه القبائل كانت معروفة بنفورها لكل سلطة غير سلطتها،

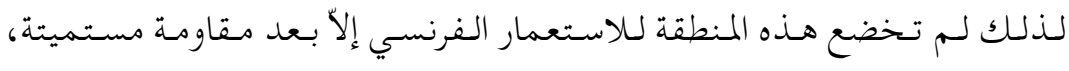

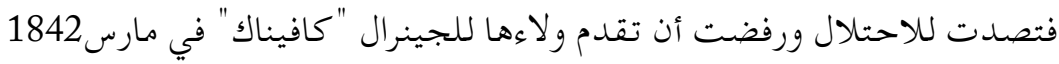

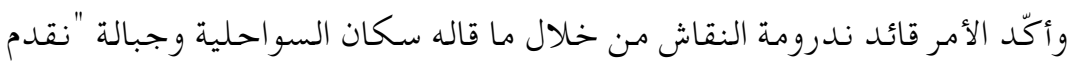
ولاءنا للجنرال ولا ننتظر سكان مسيردة أو غيرهم، ثم إن المنطقة كانت تحت إمارة

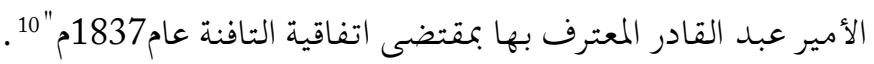

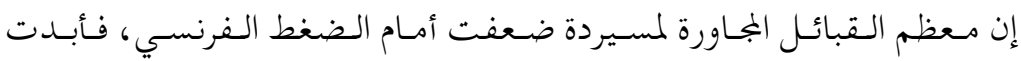

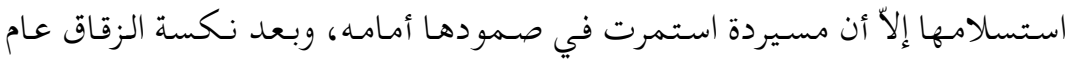

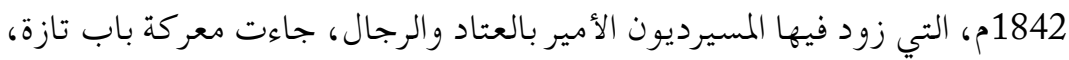

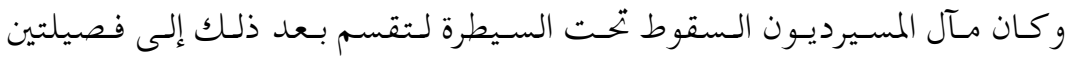
مسيردة التحاتة ومسيردة الفواقة، فسقطت الأولى عام1843 تحت قوات الجنرال

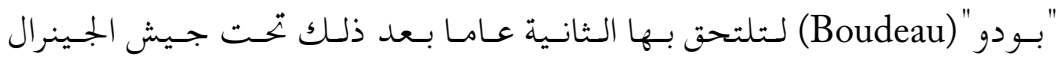
"لامورسيار" (La Morcière). 
في عام1845، وبـعد اتفاقية "لالـة مغنية" الـتي اخضعت القبائسل للسـلطة الجزائرية، التف المسيرديون حول الأمير عبد القادر من جديد، وخاضوا في جبل كركور -ليس بعيدا عن مقام سيدي إبراهيم- أولى العمليات بالمنطقة، وقد أبلوا فيها بالاء حسنا، كما سقطت القوات الفرنسية أسفل من جبل كركور بقليل في 23 سـبتمبر1845، بـقيادة "كـورب دي كـونسيار" ، حسيث انهزم الـفيلق الـثالـث والسادس والسابع، كما انهزمـت بـالقرب مـن مقام سيدي الطاهـر قوات النجـدة بقيادة "برحاو و فرومان" وعلى الرغم من هذه الانتصارات فقد خضع المسيرديون ونهائيا للسيطرة الفرنسية عام1847 11.

\section{4 انقسام مسيردة وتسمياتها}

بعد الخضوع للاستعمار الفرنسي قسمتها إلى قسمين يفصل بينهما الطريق الوطني رقم(7) الّذي يربط بين مغنية وعين عجرود، فالقسم الشمالي وهو ما بين البحر والطريق سمي ( مسـيردة التحاتة ) وقـد وقع تحت الضغط الفرنسي بـقيادة

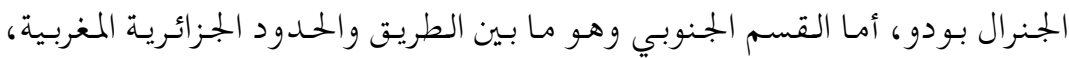
وكانت تحت حكم الجنرال لامورسيار ${ }^{12}$

وبعد استسلام أهل مسيردة نهائيا للاستعمار ، إلاً أن الأهالي بقوا على رفضهم وغضبهـم لكل قانون جـديد تسنه فرنسا وتحاول تطبيقه عليهم، فقد رفضوا دفع الضرائب التي فرضها الاستعمار عليهم، ولم يمتثلو الها إلاً بعد ما تدخلت القوات العسكرية.

لقد عرفنا أن المنطقة قسمت إلى قسمين في ظل الحلكم العسكري، فقد بقيت تتخبط تحت ضغطه إلى غاية1922، حيث خضعت للسلطة المدنية وبعد هـذا، قسمت إلى16 دوارا هي على التوالي : لبخاتة، بـني سـرات، لـقاوة، وريـاش، 
بـيدر، أولاد بـن عـايـد، أولاد سـيدي سـليمان، أولاد بـن يـحيى، لمهادة، أولاد بـن عيد، آغرم، لعنابرة، لهوارن إن كلمة مسيردة ظلت متداولة رسميا بين أهالي المنطقة حتى يومـنا هذا، أما كيف أطلقت التسمية على المنطقة، فتقول إحدى الروايات أنها جاءت نسبة إلى واقعة يحكى عنها البعض وتتمثل في وصول رجل غريـب إلى المنطقة، سئل كيف تمكنت من بلوغها رغم صعوبة المسالك إليها، وكان جوابه : لقد اتبعت المسيرذا، فقالو ا مسيردة414.

\section{5 لدلالات الثقافية للموسيقى لفرقة العرفة}

فرقة العرفة بموسيقاهـا وأغانيها ورقصها ولبسها تشكّل تراثا ثقافيا لمنطقة مسيردة بشكل خاصّ، والجزائر بصفة عامّة، تنقله الذّاكرة الشعبية عبر الأجيال لما

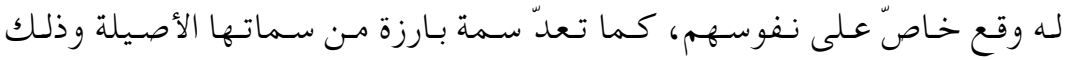
لحفاظها على الموروث الثقافي • إنّ الموسـيقى الـفولـكلوريسة في المـنطقة تـعتمد في انـتقالاتـها عـلى الـتوارث الشفهي، فذاكرتهم هي سجلّ الزّمن الّذي ظلّ يحفظها من الضّياع والتّلف خلال

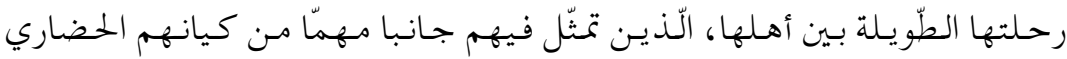

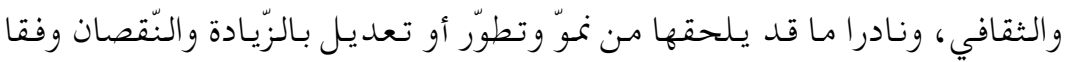

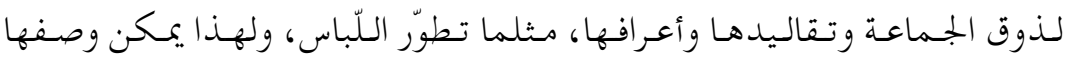
بالأصالة والتأليف الجماعي . وفي تأليفها، لا تستند على أسس علمية دقيقة بقدر ما تعتمد على ضربـة

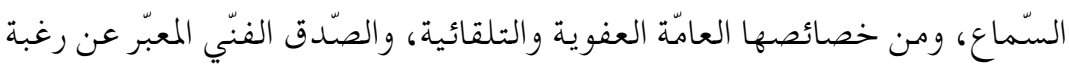

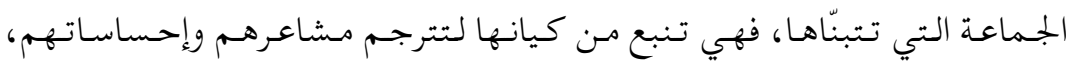
وتحقّق أغراضهم، وتكمل متعتها دون انتظار لشهرة أو كسب مادّي "وإذا قلنا أنّها 
عـفويـة وتـلقائية، فهـذا لا يـنفي عـنها خصائصهها الفنية وقو الـبها الموسيقية في

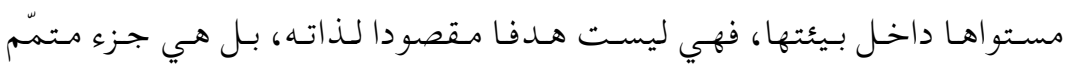

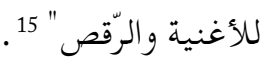

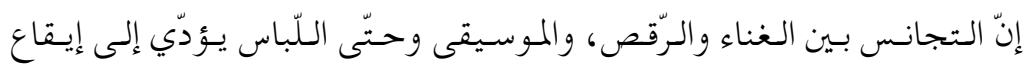

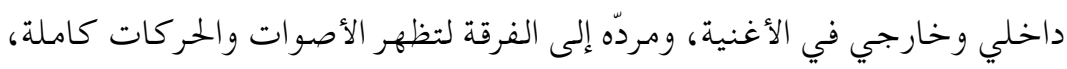

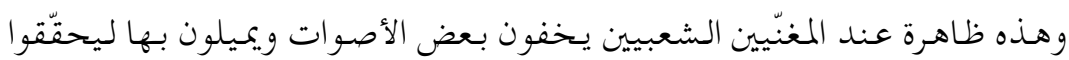
انسجاما وتماثلا في الصّوت والدّلالة بين هذه العناصر.

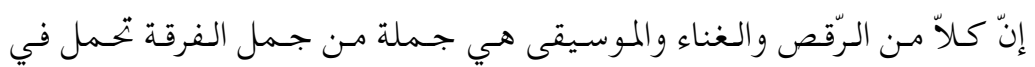

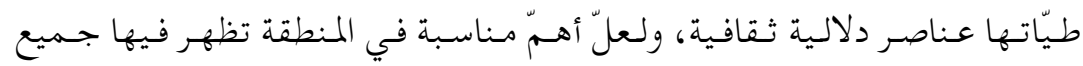

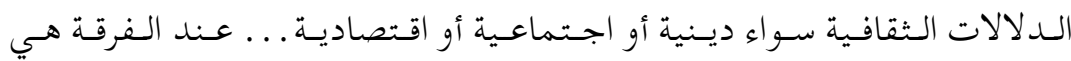

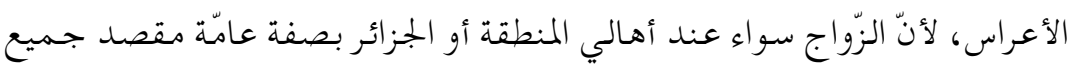

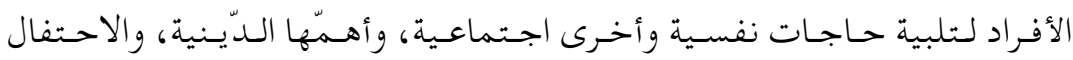
بـالزواج في مـنطقة مسـيردة مـاز ال يـحتفظ بــهـمّ العادات و الـتقاليد وإن غـابـت

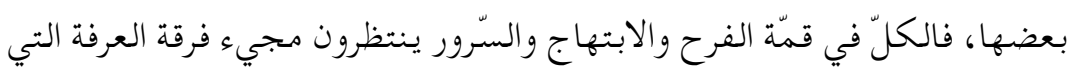
تعطي الفرح نكهته الخاصّة.

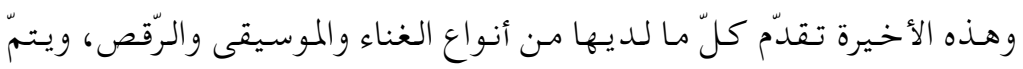
ذلك بطلب من الحاضريـن، وتحرص الفرقة في هـذا على إيصال كلّ عزف وغنـاء وحركات بوضسوح حتّى يصل المعنى واضحا للجهمهور، وهو إدراك تـامّ من دلالة

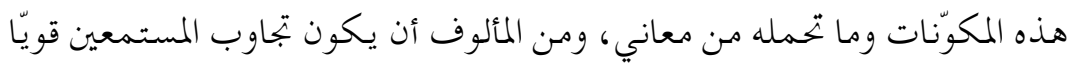

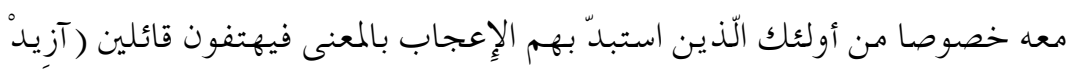

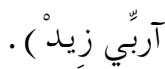


إنّ العناصر المكوّنة للفرقة، كلّ وله دلالته تريـد من خلالها أن تتميّز بها عن بـاقي الـفرق الـفولكلوريـة، لـكن الغناء ( الـكلمات ) هي الـتي يـعطى لـها القدر الكافي في إظهار هذه الدّلالات .

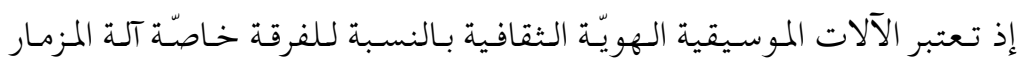

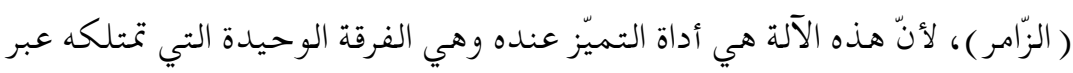

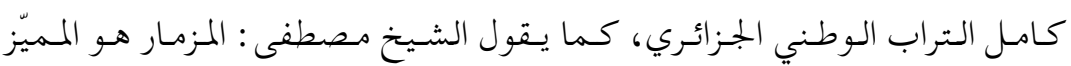
الحقيقي لفرقة العرفة بين الفرق الفولكلوريـة الأخرى، كما تعتبره الفرقة الموروث الحقيقي الّتي تتذ كرّ به أجدادها، وطبعا لا يمكن الاستغناء عن آلة البندير وأقوال. عند حضور الفرقة للحفل التّي وجّهت لها الدّعوة فيما قبل، هذا الحضور يبدأ

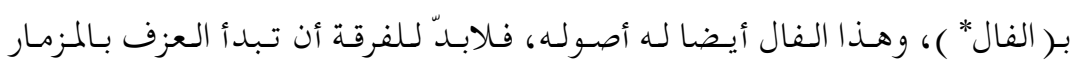

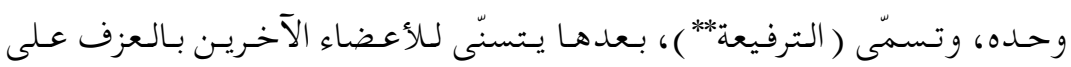

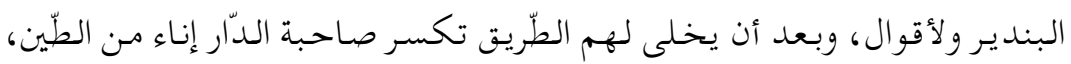
وذلك في اعتقادهم لكسر الشرّ. بعد هذا تباشر الفرقة في الغناء والرّقص، وغالبا ما تبدأ الرّقص والدة العريس، أو واحدة من أهل البيت، وترقص على أنغام رقصة الحميمة والحايطي، لأنّ هاتان

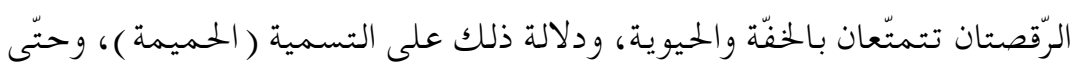

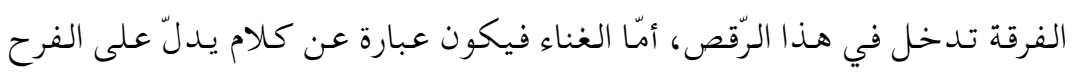

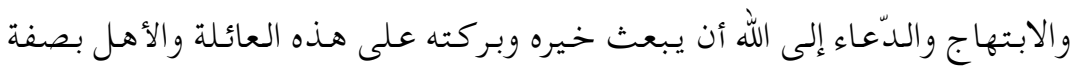

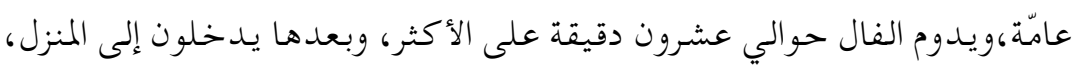

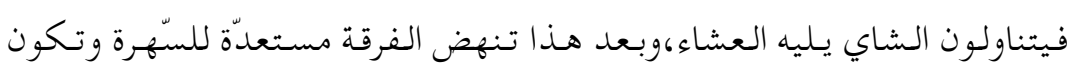

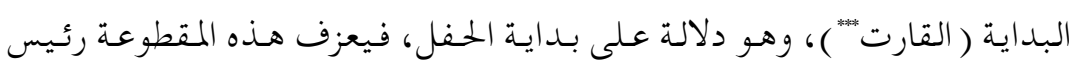
الفرقة النّافخ على آلة المزمار، فهي تقليد لا يمكن الاستغناء عنه بحيث يقوم النّافخ 
بالترحيب و تقديم التحيّة للحاضرين عن طريق هذه المعزوفة، كما يبادله الحضور التحيّة بهزّ الرّّس، وفي نهاية هذه الضرّبة يقدّم صاحب العرس قدرا من المال تعبيرا

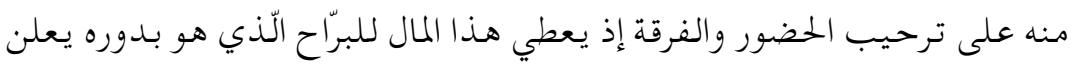
عن هذا علنيا أمام كلّ الحاضرين، وبعدها تدخل الفرقة في الغناء والرّقص لتمتع كل الحاضرين، ثمّ عند انتهاء السّهرة تودّع الجمهـور بالمزمار وحلده ويطلق عليها اسم (ضربة الصّبّاح)، وهي دلالة على نهاية الحفل .

\section{6 الدلالات الثقافية للرّقص}

إنّ الرّقص عنصر مهـمّ عند الفرقة وأغلبية الرّقص عندهم رجالي ما عدا رقصتي الحميمة والحايط، وترافق هذه الرّقصات البنادق أو العصيّ، والرّقص يتمثّل عادة

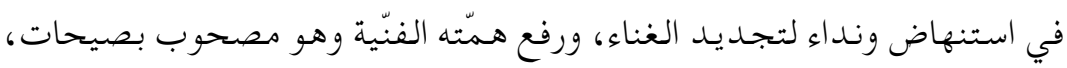
وهي تعتبر خطاب للفرقة للحفاظ عـلى المستوى الجسيّد للعزف ، كقولهـم مـثلا

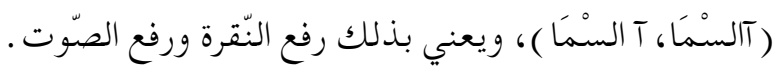

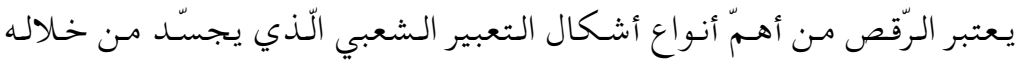

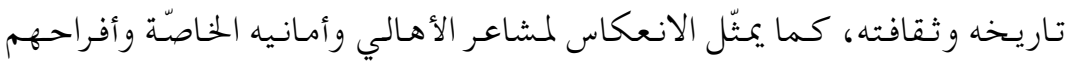

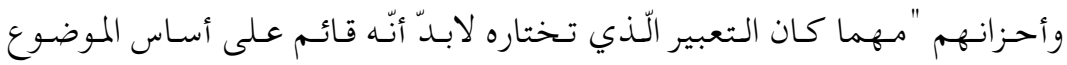

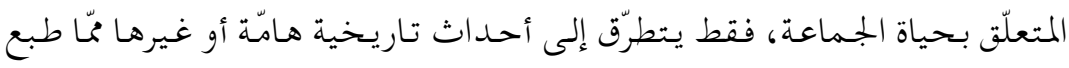

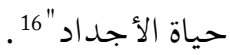

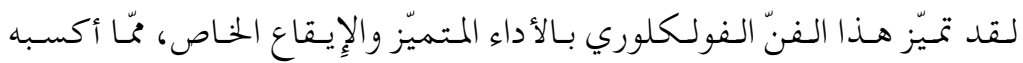

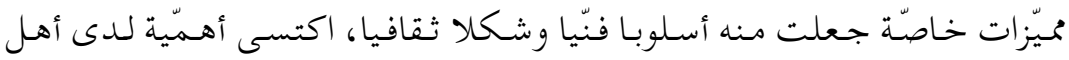
المنطقة عمومـا والفرقة خصوصا، فموضسوعاتها لا تخرج عن احستياجـات أفراد المجتمع ومختلف أذواقهم، وظروف حياتهم "وقد يتمّ التعبير في الرّقص بالحركة أو ما يسمّى بـ: ( الكوليغرافيا ) وهي وسيلة من وسائل التعبير الجسدي اللّني غالبا ما 
يـكون هـادفا، ويـعالج موضـوعات اجـتماعية تخصِ مجتمعهه وأخـرى تاريـخه،

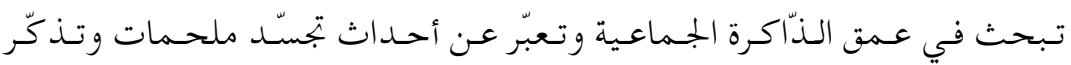

$$
\text { لبطولات ومواقف تاريخية" }
$$

وهكذا يمكن اعتبار الرّقص كلاًّ متكاملا من حياة الفرد كعضو في الجماعة، ودليلا على تششارك أفرادهـا في الأفراح والأحزان، ومـن هـنا كانـت الجماعة سمة أصلية تتميزّ بها الفرقة، اعتبارا لما تنضوي عليه الفرقة من أنواع مختلفة وأشكال

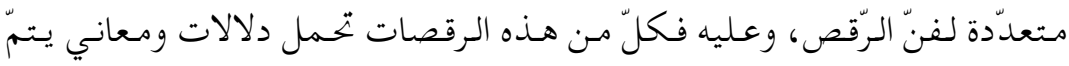

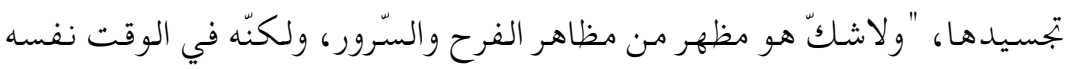
قادر على التعبير عن مظاهر أخرى منها الحماس والتعبّد" 18.

\section{( 7.1 رقصة العلاوي والنهاري}

العلاوي هي رقصة الحساب مثله مثل النهاري، فلها تقنيات موحسّدة إلاً أنّها

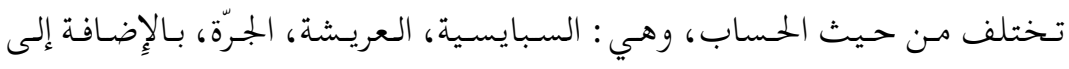
البونت ، ويمكن لهاتين الرّقصتين أن تتوقّف وتبدأ من جـديد ، و الحـركات المرافقة هي حركات الكتف التي تعبّر عن شجاعة الرّجل . كما أنّ الرقصتين تمتاز ان بطابعهما الحربي، ويمارس في نواحي عديدة من غرب

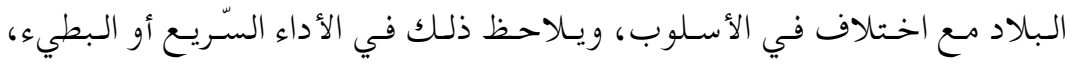

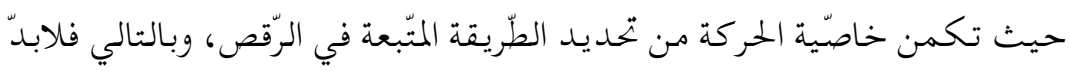
من إصدار أوامر من القائد وتلقّي تعليمات منه و كأنّ الرّاقصين في ميدان الوغى أو

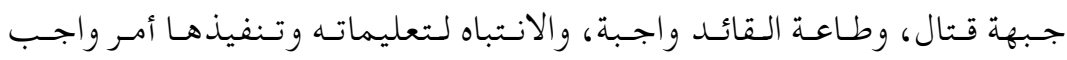
وضروري، ولا يمكن مخالفتها.

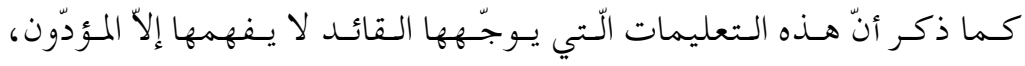
فيغيّرون الصّور والأشكال الحركية مُّا يزيدها جمالا وتعطيها صيغة فنّية غير مملّة ، 
وتببقى رقصة العلاوي والنهاري رقصة عربية لفرسـان محاربـين يـؤدونـها عقبـ الانتصارات التي كانوا يحرزونها على العدوّ، وتبدو هذه الرّقصة للمتفرّج و كأنهّا

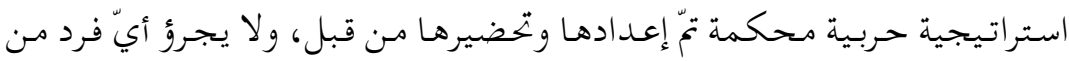
أعضاء الفرقة على القيام بأيّة مبادرة كانت و لا يمكنه أن يفعل ذلك، فالقائد هو الّذي يقوم بالمبادرات داعيا بل آمرا أعضاء فرقته بتنفيذها ويقبلون ذلك.

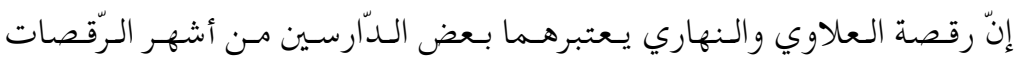
السشبية الفولكلوريـة الجـزائريـة لانتـشارهـا في بـعض المناطق الغربـية مـن الجـزائر

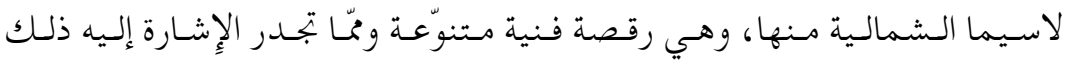
الانسجام الملاحظ بين أعضاء الفرقة والتفاهـم في الأداء، والاحترام والتقدير الّذي

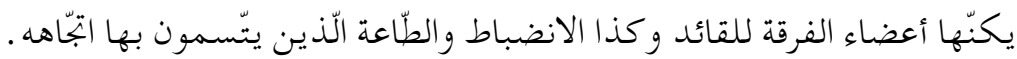
وتبقى رقصة العلاوي "محل اعتزاز الشّبّاب في كافّة غرب البلاد، وتعتبر من

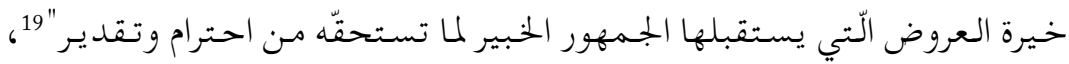
وعلى هذا الأساس فِإنّ رقصة العلاوي أهـمّيتها تكمن في طريقة أدائها الملتصقة

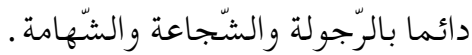

\section{2}

رقصة أحيدوس تبقى من أجمل الرقصات عند فرقة العرفة، وذلك لأنّها من أكثر الرّقصات المذكورة، تعبيرا عن الفرحة والسّرور والابتهاج لمختلف المناسبات، إلاً أنّ تأديتها عند الفرقة تختلف عن باقي الفرق خاصِّة المتواجدة بنواحي جنوب

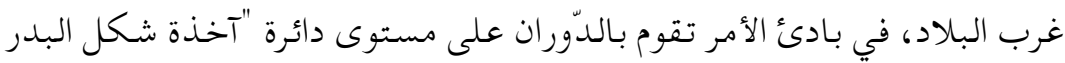

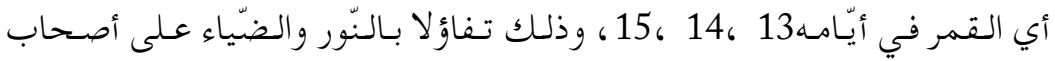


إنّ الدّوران حول الدائرة المرسومة لهم من طرف القائد والّذي هو النافخ على آلة

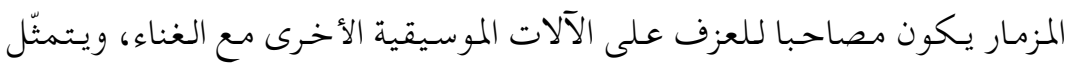
الغناء في ذكر الحبيب المصطفى، بعد هذه الخطوة تصطفّ الفرقة مقابلة للرّئيس

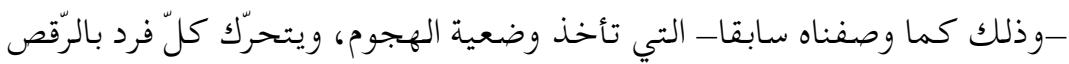

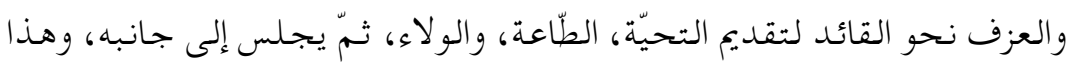
مع باقي عناصر الفرقة، وتسمية هذه الرّقصة بأحيدوس، يوحي بأنّ الفرقة بربرية

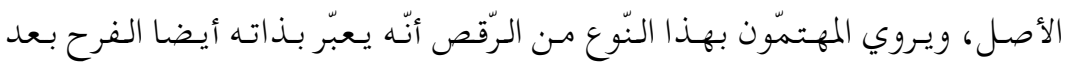
الانتصار . بـعد الانـتهاء مسن وضـعية الـتدريسب لـلهجوم وتـقديم الـتحيّة والـولاء والطظّاعـة

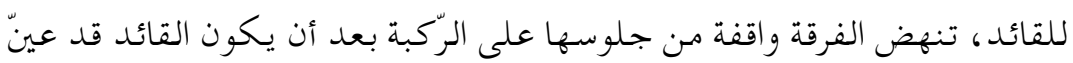

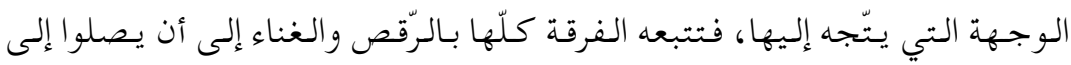

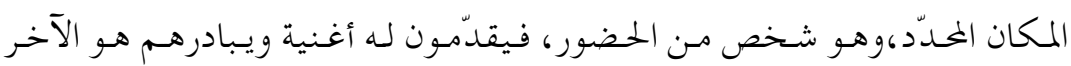
بتقديم مبلغ من المال تقديرا منه إليهم على نجاحهم في تأدية هذه الرّقصة، ويظهر ذلك التعبير الجسـدي المتناغم والمتناسق مع النّغم الموسيقي والكلمات عن مدى استعداد الممارس لخوض غمار الحرب وقدرته على مواجهة العدوّ وثقته في انتزاع

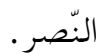
7.3 إنّ لكلمة الصفّ دلالة تتمثّل في ضبط أموره وتنظيمها منذ انتقال الفرد إلى لـ

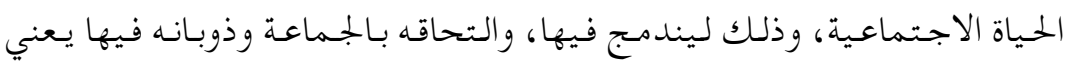

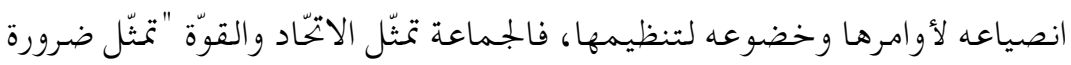
اجتماعية تستمدّ قوّتها من هذه الضّرورة لذلك من الصِّب على الأفراد الخروج

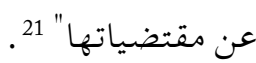




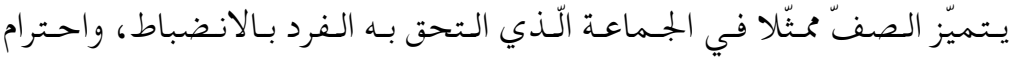
الـقو انـين ضـرورة اجـتماعية وجـــت لـتنظيم العلاقـات بـين الأفراد وتسـيير شـؤون الحياة، وهذا الانتماء يفضي إلى التلاحمى بينهم ( أفراد الجماعة ) من أجل الوحلدة

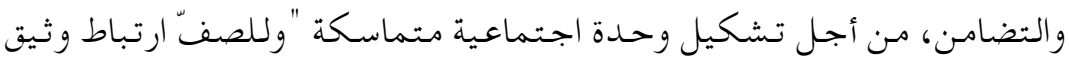
وعالقة حميمة مع الرّقص الشّعبي اللّذي يعتبر أحسد أشكال التعبير الّتي يشترك

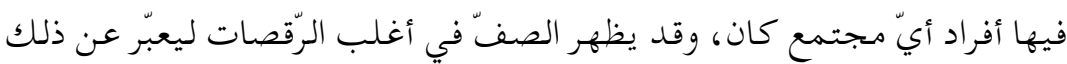
التلاحم و الانسجام، والتّناسق والتّناغم" 22. إنّ رقصة الصفّ منتشرة بصفة كبيرة في مـنطقة مسيردة فلا تعدو أن تمرّ أيّ

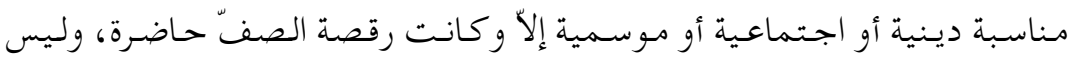
فقط عند فرقة العرفة وإنّا عند نساء المنطقة أيضا، اللّواتي يمتزن بها، وقديما عند بعض العائكلات كانـت تمارس النّساء رقصة الصفّ مع فرقة العرفة، وذلك عند حضورهم للحفل، إنّ هذا الانتشار لرقصة الصفّ في المنطقة ماهو إلآ دلالة على توحِّد أهاليها تحت نسق اجتماعي معينّ، واحترامهم للقيم الجماعية التي وجدلت بين الأهالي، وذلك كما يصفها الباحثث عماد عبد الغني : "أنساق القيم إذهي المستويات التي نحتكم إليها في عرض ذواتنا أمام الآخرين، أو هي الموجهّات التي لتهي

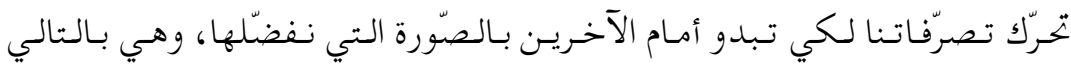
مستويات توجّهنا في إقناع الآخرين والتّأثير فيهم لتبنّي مو اقف أو معتقدات" ورقصة الصفّ كما أطلق عليها سابقا، أو ما اشتهرت بـه هي رقصة جسماعية اكتسبت عن طريق الموهبة الوراثية، كما تعدّ سجلّ لحياة فنيّة شعبية معيّنة أغلبها من القرى والبوادي تعبّر بها عن أفراحها وأحزانها، وقد يرتبط الحديث عن الرّقص

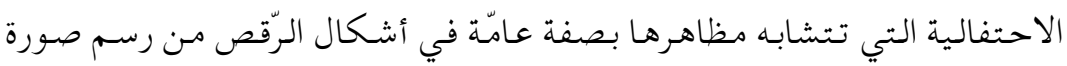
لمقاتل أو مجاهد أو وصف امرأة أو رجل أو التعبير عن حركة عامل ... 
إنّ رقصة الصف عند الفرقة هي شكل تعبيري قائم بشكل أساسي على نظام

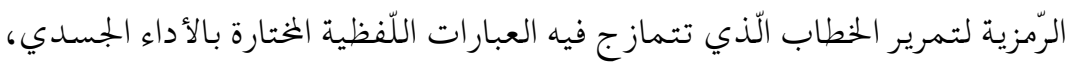

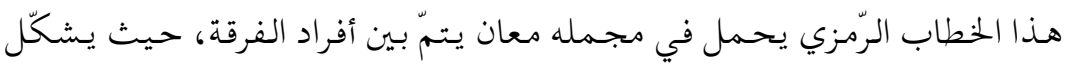
لوحة فنيّة رائعة الجمال. كما ذكرنـا سـالفا هـذه الرقصة تؤُدّى بـكثرة في مواسـم الأعراس والمناسبات الاحتفالية الأخرى ونخصِّ بالذّكر المولد النبوي الشريف، والرقص يتمّ على شكل

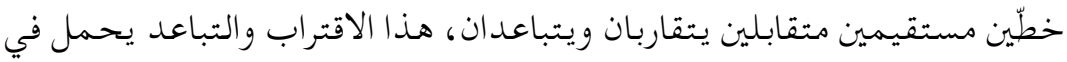

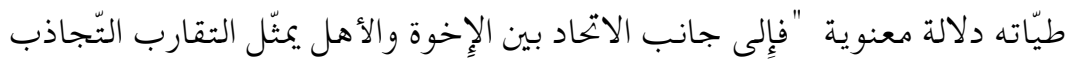
إلى حنين الأخ والأهل بعد أن كان التباعد "24. إنّ هذا الرّقص مورس بكثثرة إبّان الثورة التحريرية بشكل خاصِّ في أيّام الفرحة الكبرى للجزائريين، وهي الاستقلال ، إلاً أنّ تاريخ ظهورها يعود إلى أبعد من ذلك بكثير

\section{8 الدالات الثقافية للغناء}

تمثّل الأغنية الفولكلوريـة تراثـا شعبيا جـزائريـا فرضـت نفسها كثقافة وكفنّ فولكلوري منذ القدم، فهي أغنية متميّزة لما لها من صفات وخصائص خاصّة لا

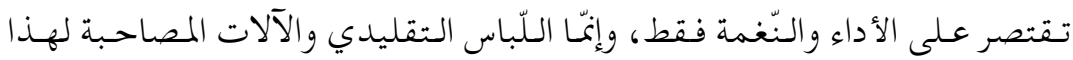
النّوع من الأغاني، يعبّر عن صورة حياة المجتمع

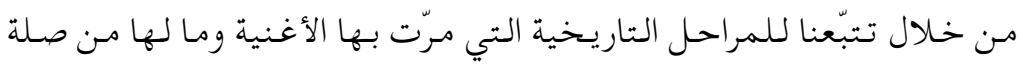
للفنّ القديم "فالكلمات عندما تتكيّف وفق لحن منغّم تشكّل واحدا من الأشكال الشعريـة الـتي هي أكـثر أصـالـة فيما عـرفـناه لأنّها تـكون مـلزمـة عـلى إتّبـاع نظظام محدود، و تضطلع بوظيفة مختلفة كلّ الاختلال عمّا هو دارج من الكلام" "25. 
تحتلّ الأغنية الفولكلورية الاهتمام الأكبر في المناسبات الخختلفة، وأوسع ميدان للأغنية الفولكلوريـة هو الزّفاف، لأنّ الاحتفال بـالزّفاف يحمل في طيّاتهـ أبعادا دينية واجـتماعية وأخلاقية واقتصادية، إذن فالأغنية الفولكلوريـة هي فــ يـتردّد على ألسنة العامّة من النّاس ريفيين وحضاريين، الّتي تستلزم وجود الجماعة، كما أنّ البعض يعتبرها حلقة أساسية من حلقات الثقافة الشعبية، فهي "مرتبطة بحياة الإِنسان في مراحلها الكاملة، كما أنّها ترتبط بمعتقداته وبعمله وبأوقات لهوه، ومسساعدة في إنجاز عمل صعب ومتنفِّس لعاطفة الإنسسان الشعبي "26، وتتجسّـد من خلال الأغنية الفولكلورية عقلية المجتمع وميولاته الفكريـة والأخلاقية، كما أنّها تكشف عن طموحاته وإرادته

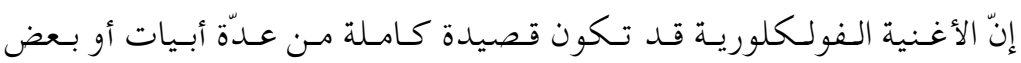
الأبيات منها .فقد احتفظ المغنّون بها لما لها من تأثير في نفوسهم، وتعبير صادق

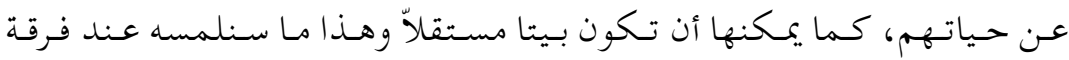
العرفة، فلهم عدّة قصائد تتـكوّن مـن بيت أو بيتين على الأكثر، تنـاقلته الأجيال بالحفظ، فتميّز هذا الغناء بالقدم، و كان دوره هو الحفاظ على الموروثات الثقافية،

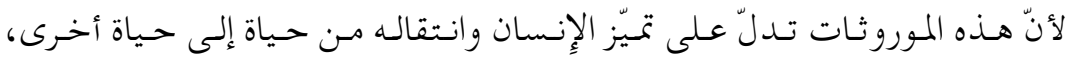

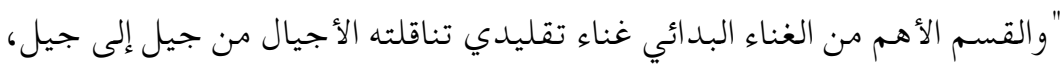
وأنّ البدائيين يؤلّفون أغانيهم دون أن يلجؤو إنبميعة الحال إلى الكتابة"27.

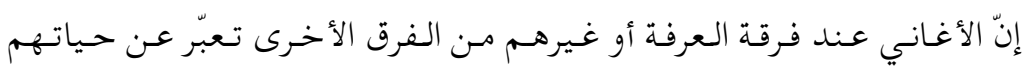

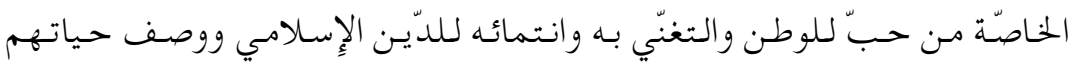

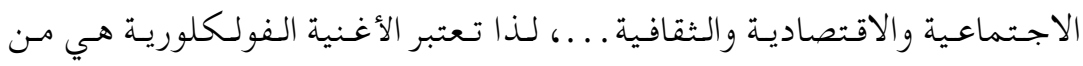
تحمل أكثر الدّلالات الثقافية للفرقة . 
من خلال دراستنا لموضوع "الموسيقى الفولكلورية الجزائرية ودلالاتها الثقافية

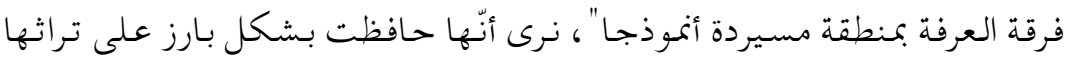
الثقافي كما هو الشأن لمعظم الفرق الفولكلورية الأخرى، في مناطق الوطن، حيث لا تزال بعض المؤشّرات والعادات الثقافية تتعايش مع غزو الثقافات الو افلدة عبر وسائل الإعلام المختلفة، كما أنّها تعتبر المرآة التي تعكس خصائص هذه الأمّة ولغة

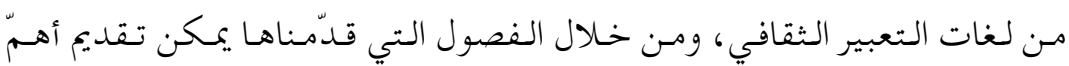
النتائج التي خلص إليها بحثنا هذا فيما يلي :

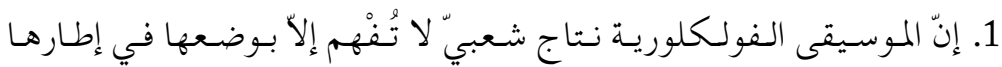
الزماني والمكاني والتاريخي اللّي أحاط بها لتصبح وثيقة هامة معبّرة بصدق، ومن

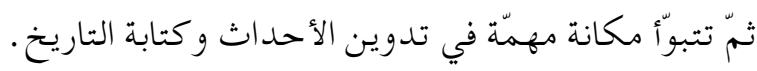
2. ساهمت الموسيقى الفولكلورية بقدر وافر في المحافظة على استمرار الثقافة

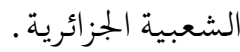
3. تتجلّى القيمة الفنّية للموسيقى الفولكلورية في إيقاظ المشاعر العميقة

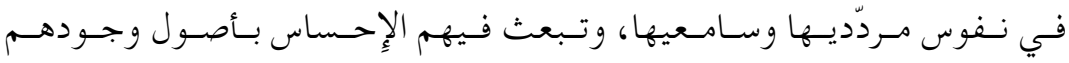
الاجتماعي والثقافي .

4. تتميّز الموسيقى الفولكلورية بالتنوّع في الموسيقى والغناء والرّقص لاسيما من حيث الشّكل والأداء. 5. تؤدي الموسيقى الفولكلوريـة دورا هـاما يـمثّل في التقريسب بـين جـميع طبقات الشعب المثقِف والأمّي والغنيّ والفقير، وهذا بشكل العام. 


\section{المصادر والمراجع}

${ }^{1}$ Revue Africaine, Gabriel Audissio, Société de géographie N68, 1927 Alger, pp. 76-77.

${ }^{2}$ Revue Africaine, Gabriel Audissio, pp. 88.

${ }^{3}$ Revue Africaine, Gabriel Audissio, pp. 79.

${ }^{4}$ Revue Africaine, Gabriel Audissio, pp. 81.

5 التيجاني الزاوي: الأغنية الفولكلورية في مسيردة، مضامينها وفنياتها، رسالة ماجستير، جامعة

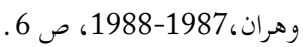

${ }^{6}$ Revue Africaine, Gabriel Audissio N68, pp. 81-82.

${ }^{7}$ Revue Africaine, Gabriel Audissio, pp. 83-84.

${ }^{8}$ Revue Africaine, Gabriel Audissio, pp. 83.

${ }^{9}$ Revue Africaine, Gabriel Audissio, pp. 86.

$$
10 \text { لتيجاني الزاوي :الأغنية الفولكلورية في مسيردة، ص } 8 \text { عن: }
$$

AZAN PAUL Sidi Ibrahim: Récit d'Afrique, Editeur militaire, Io Rue Deuton BdSt Germain 118, Paris, p. 369.

${ }^{11}$ Revue Africaine, Gabriel Audissio, p. 86.

$$
12 \text { عن السيد : محمد تربش : أول كاتب لبلدية مسيردة الفواقة. }
$$

${ }^{13}$ Revue Africaine, Gabriel Audissio, p. 87.

$$
14
$$

15 Tribus et Douard de l'Algerie, P. Acardo, Typographie et lithnographie Adolphe Jourdan, Alger, 1979, p. 103.

$$
\begin{aligned}
& 16 \text { عن السيد : محمد تربش : أول كاتب لبلدية مسيردة الفواقة. } \\
& 17 \text { عن السيد : عبد الهادي هنيني: كاتب ببلدية سوق الثلاثاء. }
\end{aligned}
$$

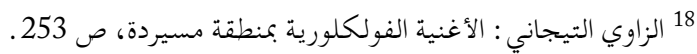

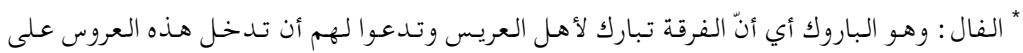

$$
\begin{aligned}
& \text { زوجها بالخير والبركة. } \\
& \text { *** الترفيعة : وهي إعلان عن حضور لفرقة العرفة حتّى يتسنّى لأهل الدّّر بترتيب أمورهم . } \\
& \text { | القارت : مقطوعة موسيقية بآلة المزمار فقط . } \\
& 19 \text { إبراهيم بهـلول: فنّ الرقّص الشعبي في الجزائر، ديوان المطبوعات الجامعية، الجزائر، 1986، ج ج }
\end{aligned}
$$


20 محمدل بوترفاس : الرقص الشعبي أنواعه وخصائصده، رسالة لنيل شهادة الماجستير في الثقافة الشعبية، جامعة تلمسان، 2006-2007، صوسر 18. 21 يسـرى جـوهـري عـرنسيطة : الـفنون الـشعبية في فلسطين، مـنظّمة التحريـر الفلسهينية، مـركز الأبحاث ، 1968، ص 62.

$$
\begin{aligned}
& 22 \text { إبراهيم بهلول : فنّ الرّقص الشعبي، ص } 01 . \\
& 23 \text { لعريف احمد : أحد مشايخ فرقة العرفة . }
\end{aligned}
$$

24 عبد الغني عماد: سوسيولوجيا الثقافة، مركز دراسات الوحدة العربية، بيروت، ط 1 ، 2002،ص صعرده

$$
\begin{aligned}
& 25 \text { محمد بوترفاس : الرّقص الشعبي أنواعه وخصائصه، ص } 94 . \\
& 26 \text { عبد الغني عماد : سوسيولوجيا الثقافة، ص } 147 \text { : } 147 . \\
& 27 \text { ميلود لعريف : عضو فرقة العرفة، ضارب على آلة البندير . }
\end{aligned}
$$

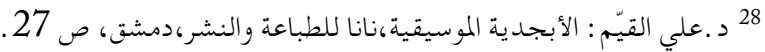

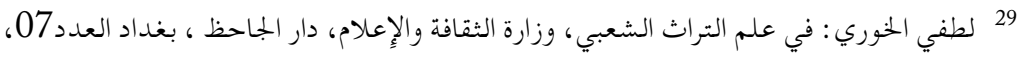

$$
\begin{aligned}
& \text { 1979، ص } 270 . \\
& 30 \text { د. علي القيم: الأبجدية الموسيقية، ص } 30 .
\end{aligned}
$$

